\title{
Statistically significant?
}

\author{
Daniel I. Sessler
}

Received: 22 July 2011/Accepted: 27 July 2011/Published online: 6 September 2011

(C) Japanese Society of Anesthesiologists 2011

To the Editor:

Hudetz and colleagues report the effect of metabolic syndrome on postoperative cognitive dysfunction after noncardiac surgery [1]. A sample-size estimate was not provided to justify the choice of 30 patients per group, which is considerably smaller than is typical for trials evaluating posopterative cognitive function.

The primary outcome is not defined, but one of two reported positive outcomes is that "the prevalence rate of postoperative cognitive dysfunction differed in the studied groups (13/30 and 8/30) in patients with versus without metabolic syndrome; $P<0.02$." The actual $P$ value for these proportions is 0.176 , a value that is well above the author's threshold for statistical significance, which was 0.05 .

\section{Reference}

1. Hudetz JA, Patterson KM, Amole O, Riley AV, Pagel PS. Postoperative cognitive dysfunction after noncardiac surgery: effects of metabolic syndrome. J Anesth. 2011;25:337-44.

An answer to this letter to the editor is available at doi: 10.1007/s00540-011-1214-4.

\section{I. Sessler ( $\square)$}

Department of Outcomes Research,

The Cleveland Clinic, 9500 Euclid Avenue,

P-77, Cleveland, OH 44195, USA

e-mail: DS@OR.org

URL: www.OR.org 